\title{
ANÁLISE DA TEMPERATURA E UMIDADE RELATIVA DO AR NO BAIRRO CASTELO, BELO HORIZONTE - MG, NO SEGMENTO TEMPORAL DE 11/09/16 A 12/10/2016
}

\author{
Isabela Mara Lima $^{(a)}$, Carlos Henrique Jardim ${ }^{(b)}$, Ricardo Alexandrino Garcia ${ }^{(c)}$, Wellington \\ Lopes Assis ${ }^{(d)}$ \\ (a) Graduanda de Geografia/Instituto de Geociências, UFMG, maraisabela.lima@ gmail.com \\ (b) Departamento de Geografia/Instituto de Geociências, UFMG, cjardim@yahoo.com \\ (c) Departamento de Geografia/Instituto de Geociências, UFMG, alexandrinogarcia@gmail.com \\ (d) Departamento de Geografia/Instituto de Geociências, UFMG, assisw@gmail.com
}

\section{Eixo: Climatologia em Diferentes Níveis Escalares: Mudanças e Variabilidades}

\begin{abstract}
Resumo
$\mathrm{O}$ presente artigo analisa a influência de fatores urbanos nas variações de temperatura e umidade relativa do ar, adotando como referencial de área o bairro Castelo, situado ao norte do município de Belo Horizonte - MG, de ocupação recente e quase inteiramente verticalizada. Os dados foram produzidos continuamente em intervalos horários durante o segmento temporal entre 11/09/2016 a 12/10/2016 e a análise considerou a relação dos dados mensurados com as características de relevo e uso da terra, sob condições atmosféricas diferenciadas. Os resultados mostraram grau diferenciado de comprometimento com fatores naturais e antrópicos, caracterizando em diversas situações a organização de clima urbano.
\end{abstract}

Palavras chave: microclimas; uso da terra; clima urbano.

\section{Introdução}

Há grande preocupação diante das interferências humanas no meio ambiente natural e suas consequências (a curto e longo prazo) que, evidentemente, comprometem um desenvolvimento sustentável. Uma dessas consequências é a alteração (micro)climática, em especial no ambiente urbano, devido a intensa expansão das cidades.

As modificações do meio ambiente natural para o surgimento de uma cidade são muitas como exposto por Cordeiro e Lima (2016), podendo ser citadas diversas práticas, tais como: canalização de rios, retirada da vegetação nativa, inserção de materiais artificiais impermeáveis (cimento e asfalto), modificação da morfometria original das vertentes, além de ser fonte extra de calor devido ao excesso de automóveis e atividades industriais. Forma-se então um clima característico neste ambiente antrópico, o clima urbano, abordado por Monteiro (1976) como um sistema que abrange o clima de um dado espaço terrestre e sua urbanização. Essas alterações assumem proporções significativas, em alguns casos, coincidindo com a formação de climas urbanos como demonstra Assis (2010) na cidade de Belo Horizonte identificando 
estruturas próprias desse sistema como "ilhas de calor" ou, até mesmo, imprimindo um ritmo próprio de variações ao clima das cidades, como mostra Azevedo (2001) na cidade de São Paulo.

Jardim e Silva (2016) também identificaram indícios de imposição de um ritmo climático urbano à cidade de Belo Horizonte utilizando metodologia semelhante de Azevedo (2001) para tratamento de dados de temperatura do ar, agrupando os valores por dia da semana e comparando segmentos temporais anuais relativamente antigos (1961-2001) aos recentes (2000-2010). Teoricamente, esses segmentos temporais representariam, respectivamente, condição na qual a cidade não teria produzido alterações no ambiente a ponto de imprimir-lhe um ritmo próprio de variações dos elementos climáticos contra uma situação em anos mais recentes representativa de uma condição de clima urbano, com a imposição de um ritmo próprio de clima que, no caso de Belo Horizonte, coincide com picos de temperatura do ar (principalmente nos valores mínimos), às sextas-feiras.

Por outro lado é importante que fique claro a participação de fatores naturais como o relevo e as massas de ar, tanto acentuando quanto forçando a dissipação de estruturas próprias desse tipo de clima, ou seja, o clima urbano não é uma condição permanente dependendo da combinação local e em microescala entre fatores naturais e antrópicos.

A cidade de Belo Horizonte foi e continua sendo destaque de constante crescimento urbano, e a principal causa se deu pela expansão dos loteamentos a preços mais acessíveis para a classe média e baixa. Em decorrência disso, há certo descontrole da administração municipal sobre as regras de uso e parcelamento do solo, provocando um grande crescimento da cidade, assim como maior pressão e saturação dos serviços públicos da capital.

Um dos mais recentes bairros de Belo Horizonte, o bairro Castelo, também surgiu seguindo esta lógica, com o início da delimitação e venda de loteamentos. Fundado na década de 1970, o Castelo foi inicialmente estabelecido mediante a divisão de duas grandes fazendas existentes na região (Fazenda da Serra e a Fazenda São José), que em seguida começaram as demarcações e construção de lotes, dando início a urbanização do bairro recém-criado. Nos dias atuais, o Castelo passa por um crescimento imobiliário extremamente acelerado, em especial de grandes edificações residenciais, a fim de atender a procura de novos moradores por este bairro. Neste contexto, o bairro Castelo assume característica de extrema importância para este estudo, haja vista que consiste em uma região de contínua expansão imobiliária e verticalização de edificações (fatores determinantes na alteração do meio natural e, consequentemente, do clima urbano em microescala).

O bairro Castelo, localizado na regional Pampulha de Belo Horizonte (figura 1), é caracterizado por ser predominantemente residencial, ainda que o bairro venha apresentando um constante crescimento 


$\begin{aligned} & \text { XVII Simpósio Brasileiro } \\ & \text { de Geografia Fisica Aplicada }\end{aligned}$
$\begin{aligned} & \text { I Congresso Nacional } \\ & \text { de Geografia Física }\end{aligned}$

comercial e de serviços, para atender a população domiciliar (localizadas em sua maior parte nas avenidas Miguel Perrela, Tancredo Neves, Altamiro Avelino Soares e na Rua Romualdo Lopez Cançado). Nos aspectos físicos, o bairro Castelo está localizado em área de relevo predominante pouco movimentado, com vertentes de baixo valor de declividade (cotas altimétricas variando entre 840 e 870 metros). A cobertura do solo é composta por sua grande parte de asfalto (salvo a presença de alguns lotes vagos na região), justamente devido ao intenso e constante crescimento imobiliário no bairro, como observado na figura abaixo (figura 2). Um exemplo visível desta dinâmica é possível ser observado de acordo com as fotos presentes (figura 2), que apresentam imagens de três diferentes fases da construção de um novo supermercado no bairro, realizado em poucos meses. A somatória de todos estes fatores, influencia diretamente no balanço de energia no local, desencadeando características microclimáticas únicas ao longo de todo o bairro.
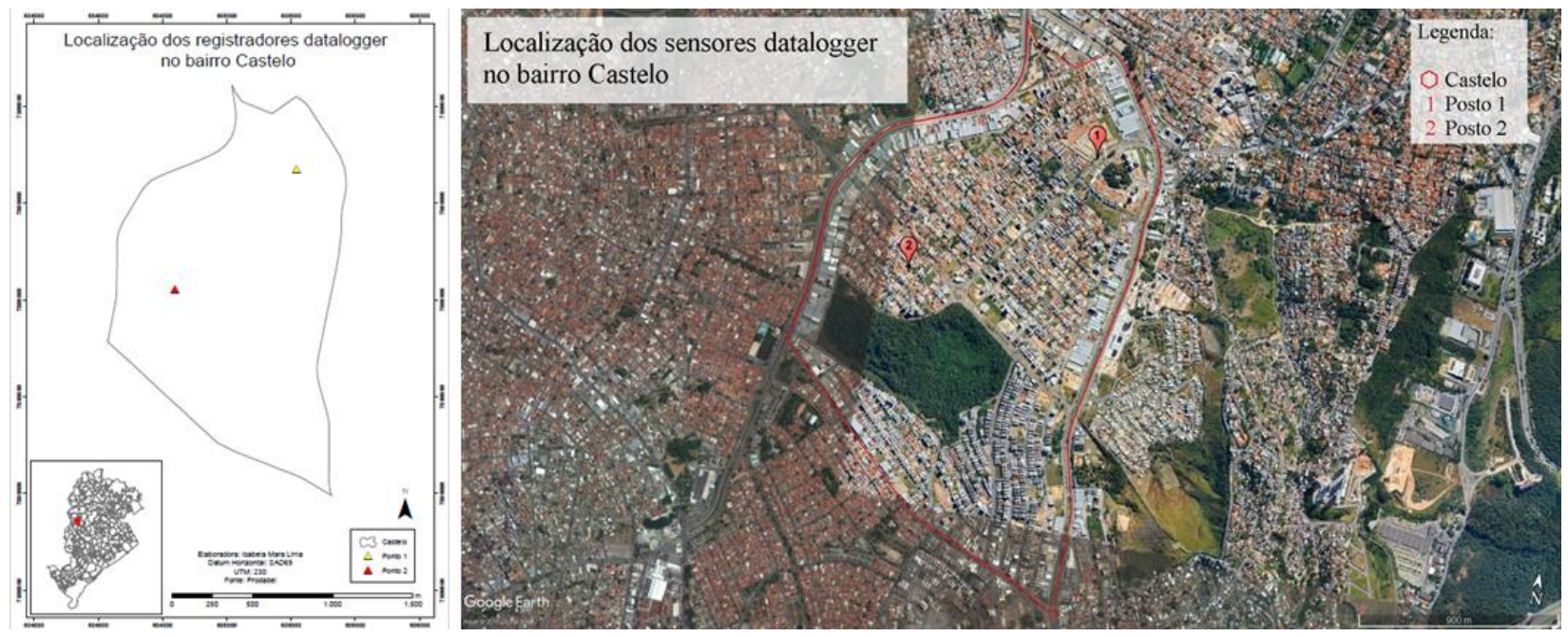

Figura 1 - Localização da área de estudo. Fontes: Google Earth (2017). Organização: Isabela M. Lima.

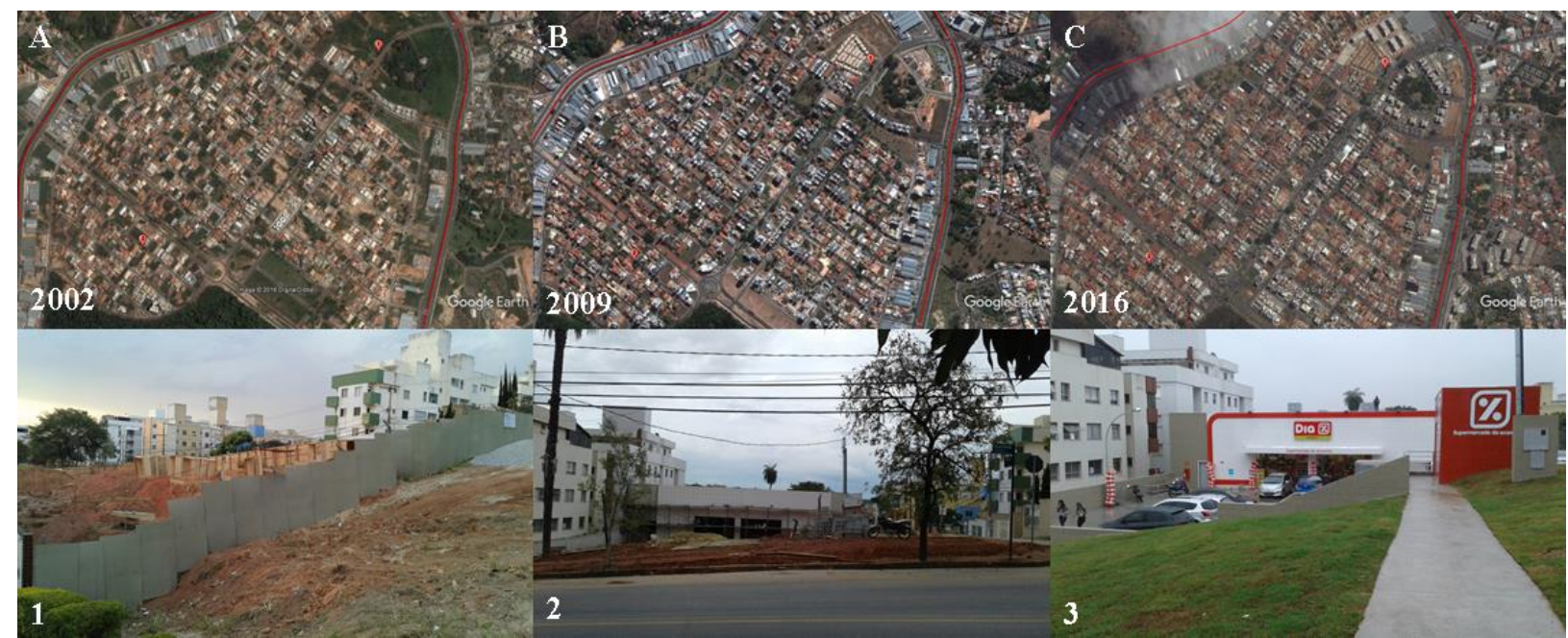




\section{OS DESAFIOS DA GEOGRAFIA FÍSICA NA FRONTEIRA DO CONHECIMENTO \\ Instituto de Geociências - Unicamp \\ Campinas - SP \\ 28 de Junho à 02 de Julho de 2017}

Figura 2 - Evolução do crescimento do bairro Castelo e construção de um supermercado no bairro: A. Ano de 2002;

B. Ano de 2009; C. Ano de 2016; 1. Terraplanagem e início das obras; 2. Construção; 3. Inauguração.

Organização e fotos: Isabela M. Lima.

\section{Procedimentos metodológicos}

Os procedimentos metodológicos adotados neste trabalho contam com algumas etapas, no qual a primeira consistiu em um levantamento bibliográfico, mediante consulta de estudos monográficos, dissertações, teses, livros, artigos etc. Em seguida foi definido o local de estudo, o bairro Castelo, situado na regional Pampulha (norte no município de Belo Horizonte), pelo fato de ser um bairro com intenso crescimento imobiliário na capital mineira. Posteriormente, foram escolhidos os pontos para distribuição pelo bairro e instalação dos equipamentos para a mensuração dos dados.

Ao todo dois pontos foram definidos e marcados suas respectivas posições geográficas por intermédio de GPS (figura 3), a fim de assinalar suas localizações. Em seguida, em ambos os pontos, foram instalados sensores automáticos do tipo data Logger (modelo HT 4000), programados para leituras horárias e instalados no interior de abrigos meteorológicos (figura 3) a fim de protegê-los de intempéries, intensa radiação solar, além de proporcionar maior uniformidade para os resultados mesurados.

Acerca dos pontos selecionados, ambos foram instalados em áreas residenciais: o primeiro deles está localizado a aproximadamente $849 \mathrm{~m}$ de altitude e possui coordenadas S $19^{\circ} 52^{\prime} 33.32^{\prime}$ ', W $43^{\circ} 59^{\prime}$ 42.04', em uma área residencial de condomínio fechado. O segundo ponto corresponde às coordenadas $\mathrm{S}$ $19^{\circ} 52^{\prime} 54.1^{\prime}$, , W $44^{\circ} 00^{\prime} 06.8^{\prime \prime}$ ' e situa-se a $845 \mathrm{~m}$ de elevação, também em uma área residencial do bairro Castelo. Este primeiro ponto dispõe de alguns aspectos distintos em relação ao segundo, como estar situado em uma larga avenida de grande movimento no bairro, além do fato do sensor ter sido instalado em área ampla e vegetada do condomínio residencial, mais especificamente na galhada de uma árvore de grande porte (figura 3). O segundo ponto, em contrapartida, está localizado em via menos ampla e mais afastada do grande fluxo do bairro, além de contar com maior número de residências próximas umas das outras (figura 3).

A fim de minimizar transtornos na pesquisa, estes locais de mensuração foram definidos diante alguns aspectos: (1) locais em ambientes externos e de livre circulação, (2) segurança, para se evitar furtos, e (3) ambientes residenciais de pessoas de confiança (no caso, de dois autores deste presente artigo). Apesar da dificuldade de se escolher pontos de mensuração para micro escalas, estes locais se mostraram como mais pertinente diante limitações de instalação e disponibilidade de aparelhos. Tais dificuldades de fato ocorrem, visto que inicialmente esta pesquisa contava com um sensor em um parque existente no bairro, que infelizmente foi furtado, impedindo a comparação dos dados residenciais, com aqueles de um 
XVII Simpósio Brasileiro de Geografia Física Aplicada

I Congresso Nacional

de Geografia Física
OS DESAFIOS DA GEOGRAFIA FÍSICA NA FRONTEIRA DO CONHECIMENTO

Instituto de Geociências - Unicamp

Campinas - SP

28 de Junho à 02 de Julho de 2017

ambiente vegetado. Devido a este acontecimento, foram realizadas análise das séries temporais dos dados da estação meteorológica oficial do INMET de Belo Horizonte - Pampulha, localizado no campus da UFMG, utilizada como controle local das variáveis climáticas.
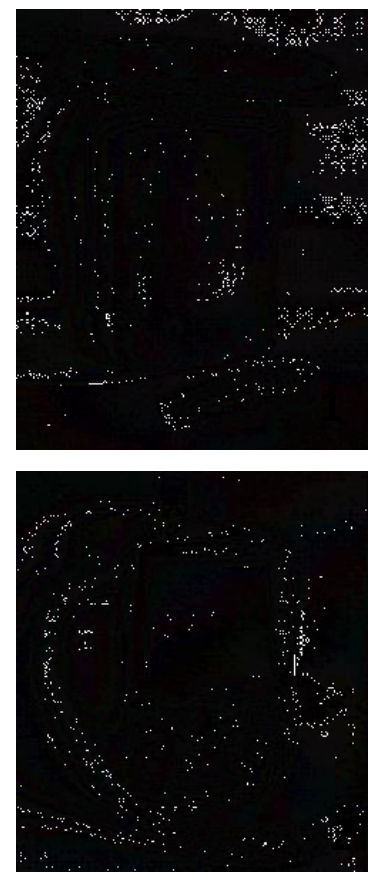
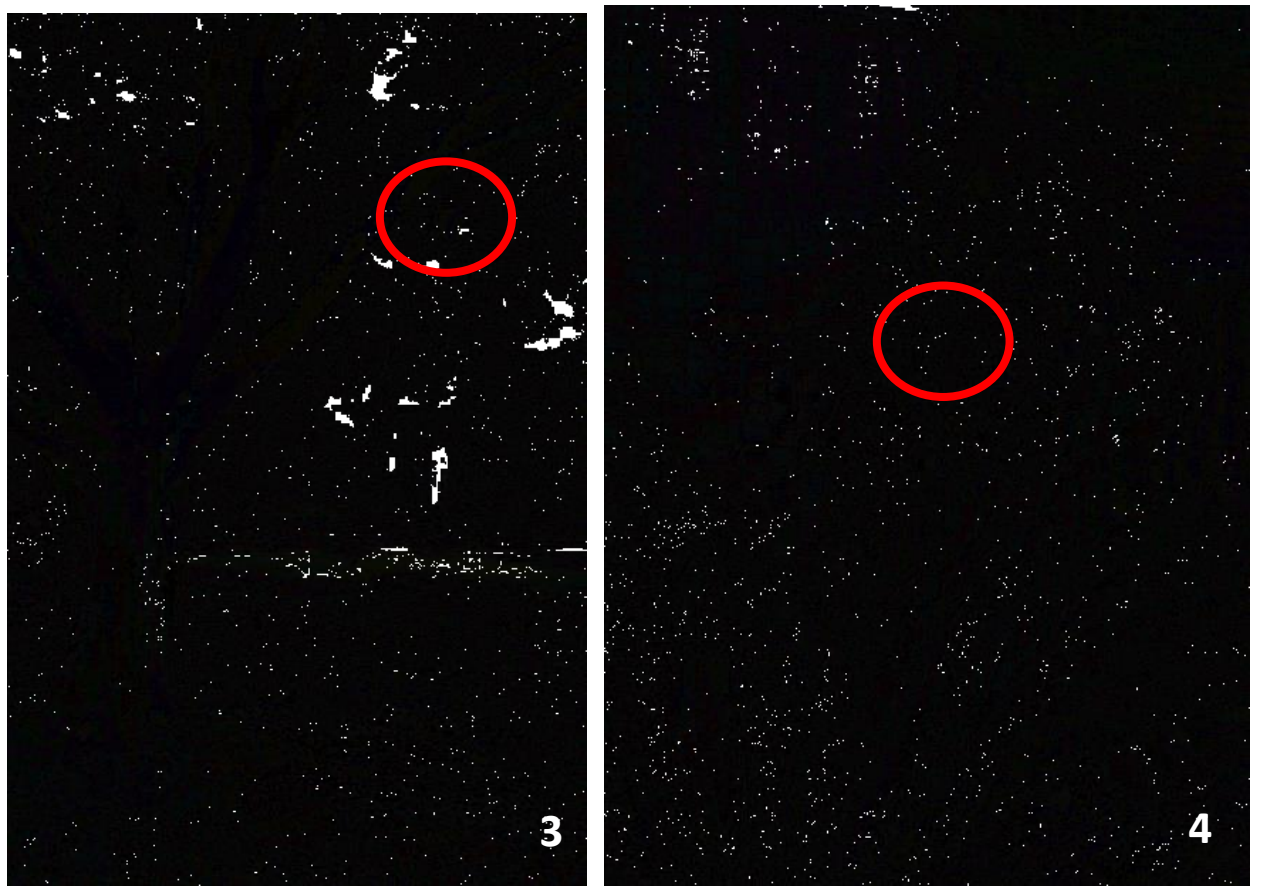

Figura 3 - Equipamentos utilizados e locais de instalação dos postos: 1. Abrigo e registrador data Logger de temperatura e umidade relativa do ar; 2. GPS; 3. Posto 1 na Av. Miguel Perrela; 4. Posto 2 na Rua

Castelo Serpa. Organização e fotos: Isabela M. Lima.

Ao todo o período de coleta compreendeu o segmento temporal entre 11/09/2016 a 12/10/2016. Ao final desse período os registradores foram recolhidos e os dados baixados para análise. As séries de dados horários de temperatura e umidade relativa foram analisadas de forma comparativa, para as três estações (as localizadas no bairro Castelo e a estação oficial do INMET), a fim de avaliar as relações entre essas variáveis mensuradas com os fatores de superfície (vegetação e topografia) e atmosféricos (sistemas atmosféricos ou massas de ar). Para melhor visualização e mais fácil compreensão, optou-se pela construção de gráficos, cujo produto mostrou-se adequado em termos de representação, capaz de ilustrar de forma contínua e simultânea a variação dos elementos climáticos com os sistemas atmosféricos em um dado intervalo de tempo. Estas relações apoiam-se na ideia de "análise rítmica" proposto por Monteiro (1971, p. 9). Segundo o autor:

(...) o ritmo climático só poderá ser compreendido através da representação concomitante dos elementos fundamentais do clima em unidades de tempo cronológico pelo menos 
diárias, compatíveis com a representação da circulação atmosférica regional, geradora dos estados atmosféricos que se sucedem e constituem o fundamento do ritmo.

Realizadas estas etapas, foram examinadas imagens de satélite e cartas sinóticas (disponíveis nos endereços eletrônicos <www.cptec.inpe.br> e <www.mar.mil.br>) a fim de analisar e caracterizar a influência das condições atmosféricas do segmento temporal em questão.

\section{Resultados}

Durante o período da coleta de dados, as condições atmosféricas foram, em sua maior parte, bastante semelhantes, com tempo estável na maior parte dos dias de estudo. As condições atmosféricas para este segmento temporal alternaram entre a ação do ASAS (Alta Subtropical do Atlâtico Sul) e a ação da MPAt (Massa Polar Atlântica tropicalizada ou em vias de tropicalização), para as situações de tempos estáveis. As situações de instabilidade se deram próximas ao início do mês de outubro, em que as condições atmosféricas foram marcadas pela ação de uma linha de instabilidade presente no estado de Minas Gerais, migrando para norte nos dias seguintes. Tendo isto em vista, foram escolhidos dois dias de condições singulares e distintas do segmento temporal, um dia caracterizado como estável e um segundo dia retratando condições de instabilidade atmosférica.

A primeira data escolhida foi o dia 18/09/2016, cujas condições mostraram relação com a ação da MPA tropicalizada, juntamente com a presença de núcleos de baixa pressão no interior do continente, como mostrado na figura 3. Além disso, este dia também foi escolhido por apresentar um dos maiores valores de amplitude térmica diária em comparação aos outros dias do segmento temporal (amplitude de aproximadamente $15,0{ }^{\circ} \mathrm{C}$ ), quando o período de maior temperatura correspondeu à parte da tarde (entre $13 \mathrm{~h}$ e $18 \mathrm{~h}$ ), em contraposição ao intervalo de tempo que abrangeu os horários entre $00 \mathrm{~h} \mathrm{e} 07 \mathrm{~h}$, conforme observado na figura 4. A umidade relativa para este mesmo dia não ultrapassou os $70 \%$, confirmando a ação de sistema estável. As variações de umidade mostram relação contrária à dinâmica da temperatura, visto que apresentava suas mínimas no período da tarde e as máximas de madrugada e pela manhã (figura 4), devido à formação de orvalho neste horário.

O período de maior instabilidade foi observado no dia 04/10/2016, devido à presença de uma linha de instabilidade (figura 3), causado pela gradiente de temperatura elevado entre o oceano e continente. As variações de temperatura para este dia permaneceram relativamente constante, como mostrado na figura 4 , em que sua amplitude térmica diária foi equivalente a $3,2^{\circ} \mathrm{C}$ (uma das menores do período de estudo), devido aos altos valores de umidade relativa do ar (acima dos 80\%) ao longo do dia (figura 4), indicando evento de pluviosidade contínuo neste dia. 

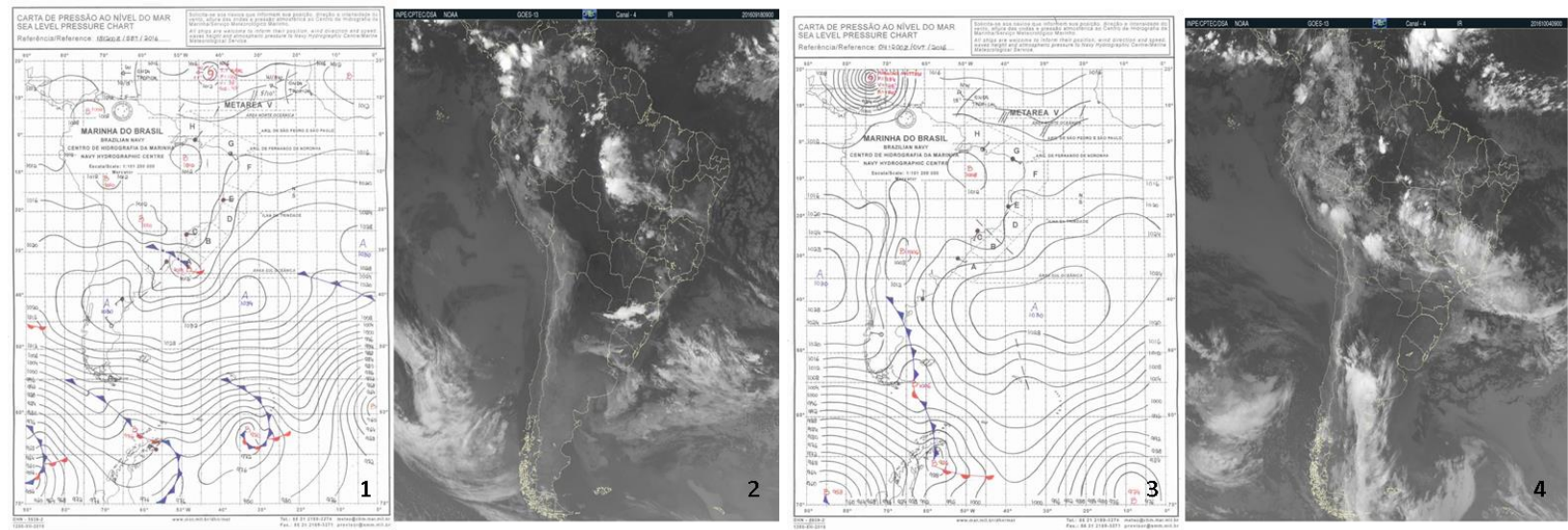

Figura 3 - Imagens de satélite e cartas sinóticas referentes às situações estudadas: 1. Carta sinótica referente ao dia 18/09/2016; 2. Imagem de satélite referente ao dia 18/09/2016; 3. Carta sinótica referente ao dia 04/10/2016; 4. Imagem de satélite referente ao dia 04/10/2016. Fontes: www.cptec.inpe.br e www.mar.mil.br.

Organização: Isabela M. Lima.

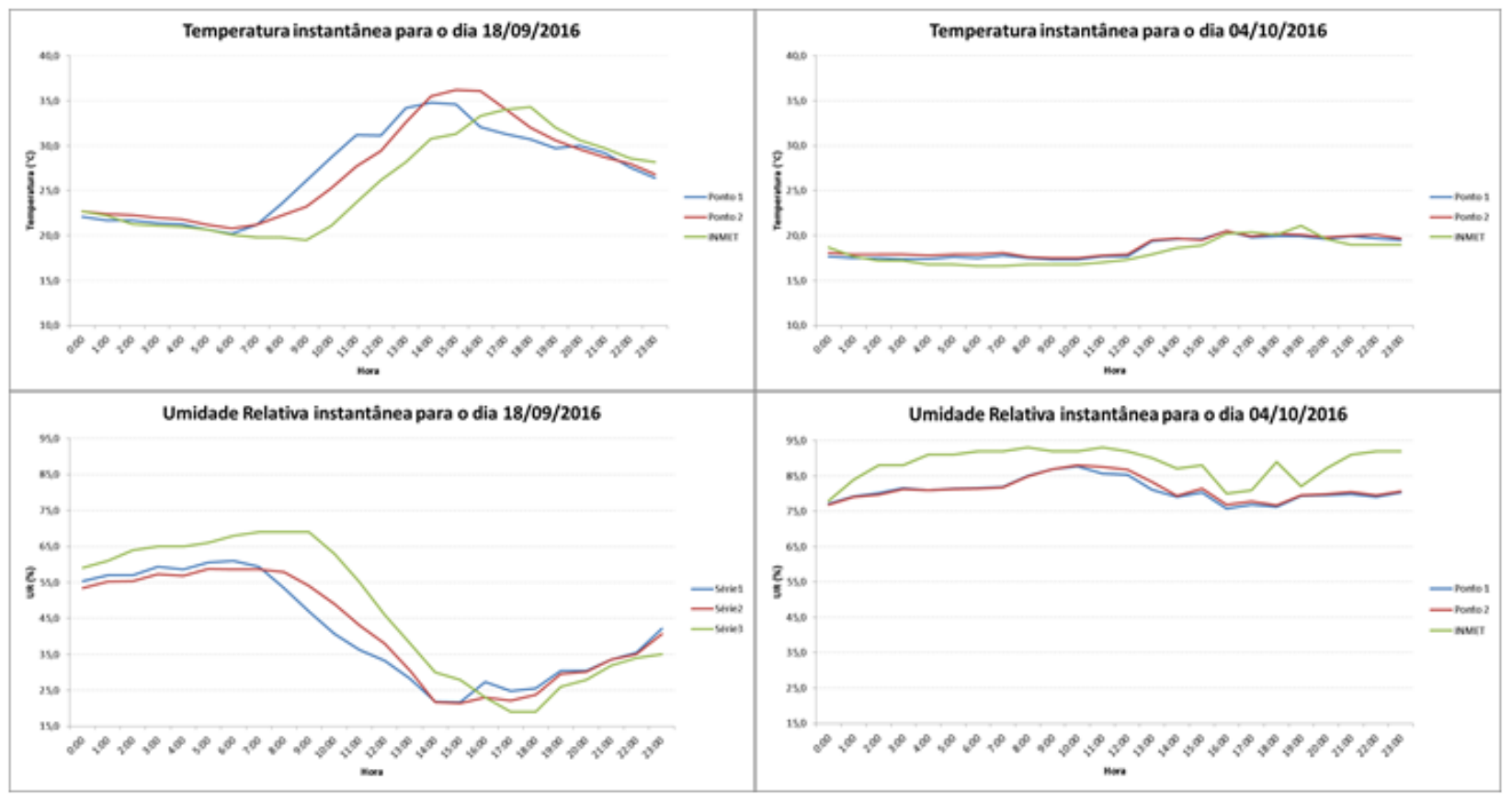

Figura 4 - Variação da temperatura e umidade relativa do ar para os dias 18/09/2016 e 04/10/2016.

Organização: Isabela M. Lima. 
Sob as condições de tempo estável do dia 18/09/2016 os maiores valores horários de temperatura e de amplitude foi decorrente da maior disponibilidade de calor sensível relativo à entrada de radiação solar direta. A absorção dessa radiação pelas estruturas urbanas (edifícios, pavimento etc.) as transforma em fontes passivas de produção de calor, cujo saldo soma-se àquele produzido de forma natural associado ao saldo positivo experimentado anualmente pela faixa de latitude onde se encontra Belo Horizonte, acrescido de fontes ativas oriundas de máquinas e equipamentos em geral e metabolismo humano, temporariamente armazenado no sistema considerando as características dos materiais empregados na construção civil, com baixo valor de calor específico e elevada capacidade e transmissividade térmica, quando comparados a estruturas orgânicas da vegetação. As diferenças de temperatura identificadas entre a estação meteorológica do INMET situada na estação ecológica de UFMG com os postos do bairro Castelo alcançaram valores entre $3,0^{\circ} \mathrm{C}$ e $5,0^{\circ} \mathrm{C}$ (superiores no bairro Castelo) e até $20 \%$ inferiores nesses mesmos locais.

Em condições de tempo instável, com elevada nebulosidade (8/8) e ocorrência de chuva, caso do dia 04/10, associada com a formação de uma linha de instabilidade sobre grande parte do território de Minas Gerais, as diferenças de temperatura entre os postos do Castelo foram praticamente nulas durante parte do período monitorado, diferindo em apenas poucos décimos de grau Celcius. E mesmo comparando com a estação meteorológica essas diferenças (na estação meteorológica) permaneceram inferiores em $1,5^{\circ} \mathrm{C}$ durante a maior parte do período.

Nessas condições a elevada nebulosidade obstrui parte da entrada de radiação direta implicando em menor absorção e saldo radiativo disponível na forma de calor, atenuando as diferenças de temperatura. A própria disponibilidade de água nessas ocasiões transfere para o ambiente suas propriedades de elevado calor específico retardando as variações de temperatura, além de propiciar aumento da evaporação cujo processo consome grande parte do calor sensível disponível no ambiente. Deve-se levar em consideração a ocorrência pontual de vegetação no bairro Castelo em contraposição à estação meteorológica que, além influenciar na obstrução de parte da entrada da radiação solar, utiliza a energia disponível no ambiente no seu metabolismo e acionamento da evapotranspiração que se constitui em fonte adicional de umidade para o ambiente. 


\section{Considerações Finais}

Embora a pesquisa ainda esteja em andamento, alguns aspectos podem ser apontados: (1) importância em se considerar as características das massas de ar atuantes, através da sucessão dos tipos de tempo, assim como (2) as características e distribuição da vegetação pelo ambiente.

No primeiro caso seria fundamental a quantificação das situações favoráveis ou não à formação de estruturas ligadas ao microclima urbano. Sendo identificados certos padrões microclimáticos, facilitaria a tomada de decisão do uso e ocupação do espaço urbano, podendo influenciar diretamente na instalação de estruturas urbanas (se estas forem realizadas de forma responsável), como a construção de residências (altura das edificações, espaçamentos entre construções, posição na vertente e em relação ao sol, etc.) visando o bem-estar humano.

No segundo caso, a existência de vegetação é de suma importância, haja vista as diferenças de temperatura e umidade entre a estação meteorológica do INMET no campus da UFMG e dados produzidos no bairro Castelo. Neste último local, uma possível solução para mitigação dos efeitos de intensa verticalização, não se trata apenas de plantar árvores, mas sim pela escolha de indivíduos que favoreçam sombreamento, de enraizamento não tão agressivo e adaptado às condições ecológicas, bem como replantio e retirada de prováveis indivíduos doentes.

\section{Bibliografia}

ASSIS, W. L. O sistema clima urbano do município de Belo Horizonte na perspectiva têmporo-espacial. UFMG, Belo Horizonte, 2010. 319 p. Tese (Doutorado em geografia)-Universidade Federal de Minas Gerais, Instituto de Geociências, Departamento de Geografia, 2010.

AZEVEDO, T. R. Derivação antrópica do clima na Região Metropolitana de São Paulo abordada como função do ritmo semanal das atividades humanas. Tese (Doutorado). Departamento de Geografia - Faculdade de Filosofia, Letras e Ciências Humanas - Universidade de São Paulo. 2001.

BAIRROS DE BELO HORIZONTE. Bairros da Região da Pampulha. Disponível em: <http://bairrosdebelohorizonte.webnode.com.br/bairros\%20da\%20regi\%c3\%a3o\%20da\%20pampulha-/>. Acesso em: 23 de outubro de 2016.

CORDEIRO, B. H. O. L; LIMA, I. M. Microclimas e (des)conforto térmico nas praças da regional pampulha, em Belo Horizonte/MG. In: Xll Simpósio de Climatologia Geográfica, 2016, Goiânia (GO). Simpósio Brasileiro de Climatologia Geográfica. Goiânia: Gráfica UFG, 2016. v. 12.

INSTITUTO NA CIONAL DE PESQUISAS ESPACIAIS. Divisão de Satélites e Sistemas Ambientais - Banco de

Dados de Imagens. Disponível em:
<http://satelite.cptec.inpe.br/acervo/goes.formulario.logic;jsessionid=0870CBF0FC92A8597B73CC24397819BB>. Acesso em: 22 de outubro de 2016. 


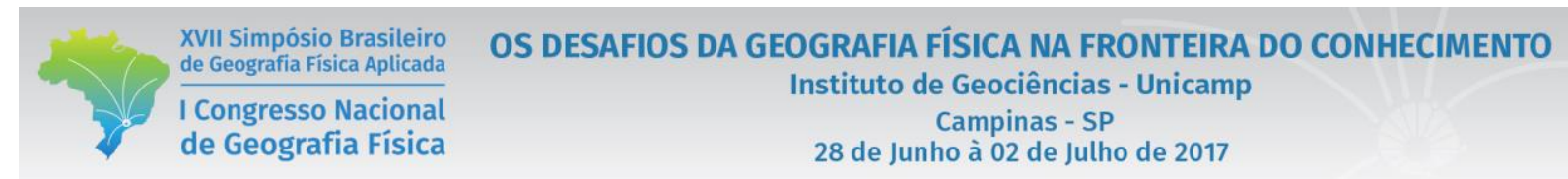

JARDIM, C. H.; SILVA, M. R.; Extremos de temperatura do ar em belo horizonte: variabilidade natural e influência do clima urbano. Revista do Departamento de Geografia, volume especial, p.83-97, 2016.

MARINHA DO BRASIL. Diretoria de Hidrografia e Navegação - Centro de Hidrografia da Marinha - Serviço Meteorológico Marinho - $\quad$ Cartas Sinóticas. <https://www.mar.mil.br/dhn/chm/meteo/prev/cartas/cartas.htm>. Acesso em: 22 de outubro de 2016.

MONTEIRO, C. A. F. Teoria e clima urbano. USP, São Paulo. 1976. 181 p. Dissertação (Mestrado) - Universidade de São Paulo. IG06-USP, 1976. 